\title{
Behavioral Neurobiology of Alcohol Addiction: Recent Advances and Challenges
}

\author{
Friedbert Weiss ${ }^{1}$ and Linda J. Porrino ${ }^{2}$ \\ ${ }^{1}$ Department of Neuropharmacology, The Scripps Research Institute, La Jolla, California 92037, and 2Department of \\ Physiology and Pharmacology, Wake Forest University School of Medicine, Winston-Salem, North Carolina 27157-1083
}

\begin{abstract}
Addictive behavior associated with alcoholism is characterized by compulsive preoccupation with obtaining alcohol, loss of control over consumption, and development of tolerance and dependence, as well as impaired social and occupational functioning. Like other addictive disorders, alcoholism is characterized by chronic vulnerability to relapse after cessation of drinking. To understand the factors that compel some individuals to
\end{abstract}

drink excessively, alcohol research has focused on the identification of brain mechanisms that support the reinforcing actions of alcohol and the progression of changes in neural function induced by chronic ethanol consumption that lead to the development of dependence. More recently, increasing attention has been directed toward the understanding of neurobiological and environmental factors in susceptibility to relapse.
The conditions that lead to excessive alcohol consumption in some individuals and not in others are complex because they involve interactions among genetic, psychosocial, environmental, and neurobiological factors. In particular, alcoholism is a multigenic disorder. Animal models, including genetic models of alcoholism that may be relevant to some forms of alcoholism, and sophisticated genetic research strategies have been directed at this specific question. Moreover, in contrast to most other drugs of abuse, the actions of which are confined to a more limited number of neurochemical or receptor systems, the pharmacological effects of ethanol that support alcohol reward and alcoholseeking behavior involve actions at multiple receptors and neurochemical systems occurring at widespread neuroanatomical sites throughout the brain. All of these factors together present unique challenges to understanding the basis of alcohol use and abuse. We focus here on recent information regarding the actions of ethanol on circuits implicated in motivation and reward, adaptations relevant for the transition to dependence and relapse, and issues relevant for the treatment of alcohol abuse that have provided new directions or new questions for the field of alcohol research.

\section{Ethanol interactions with dopamine function in the mesolimbic "reward" pathway}

Because ethanol acts as a positive reinforcer, focus on ethanolinduced activation of ventral tegmental area (VTA) dopamine (DA) function in the mesocorticolimbic reward pathway has prevailed. Other drugs of abuse have direct actions at DA synapses, but how ethanol affects this pathway has been a matter of some debate. Ethanol increases the firing of VTA DA neurons (Gessa et al., 1985; Brodie et al., 1990) through what has been shown recently to be direct excitatory cellular activation (Brodie et al., 1999). Like most drugs of abuse, ethanol elevates extracel-

This work was supported by National Institutes of Health/National Institute on Alcohol Abuse and Alcoholism through Grants AA 10531 and AA06420 (F.W.) and AA11997 and AA0929 (L.J.P.).

Correspondence should be addressed to Friedbert Weiss, Department of Neuropharmacology, CVN-7, The Scripps Research Institute, 10550 North Torrey Pines Road, La Jolla, CA 92037. E-mail: bweiss@scripps.edu.

Copyright (C) 2002 Society for Neuroscience $0270-6474 / 02 / 223332-06 \$ 15.00 / 0$ lular DA concentrations in the NAc (Di Chiara and Imperato, 1988), but recent evidence has linked this effect to direct actions at VTA DA somata rather than NAc DA terminals (Yim and Gonzales, 2000; Budygin et al., 2001).

\section{Is activation of mesolimbic DA transmission a necessary} condition for ethanol reward?

Early behavioral evidence (for review, see McBride and Li, 1998) that microinjection of ethanol into the VTA supports ethanol self-administration, ethanol dose-dependently increases DA release in the NAc in rats self-administering ethanol, and interference with DA transmission by microinjection of pharmacological agents into VTA or NAc reduces ethanol-reinforced responding has provided direct support for a role of DA in the reinforcing actions of ethanol. Manipulations of DA receptor gene expression and receptor knockout (KO) methodologies have supported this position. Mice deficient in DA D1 or D2 receptors and mice lacking DARPP-32, a phosphoprotein regulating D1 receptor function, consume less ethanol and show reduced ethanolconditioned place preference (El-Ghundi et al., 1998; Cunningham et al., 2000; Risinger et al., 2000, 2001). Moreover, injection of D2 receptor antisense oligonucleotide into the NAc suppresses alcohol intake and reverses ethanol preference in a genetically selected line of high ethanol preferring rats (Myers and Robinson, 1999), pointing to the NAc as the critical site for attenuation of ethanol reward associated with DA D2 receptor deficiency.

On the other hand, DA lesion studies with the selective neurotoxin 6-hydroxydopamine (6-OHDA) consistently show that DA denervation of the NAc does not interfere with ethanol consumption or maintenance of ethanol-reinforced responding (Ikemoto et al., 1997; Koistinen et al., 2001). Similarly, elevation of NAc DA levels by a selective DA reuptake inhibitor fails to alter ethanol self-administration (Engleman et al., 2000). These results indicate that ethanol self-administration is not dependent on NAc DA activation. Possibly, compensatory adaptations after 6-OHDA lesions may substitute for loss of DA input to NAc, or, as suggested by imaging studies in rodents (Williams-Hemby and Porrino, 1997), stimulation of NAc DA transmission is necessary for rewarding effects associated with low-dose stimulant actions of 
ethanol but not essential for other aspects of reinforcing actions of ethanol (e.g., anxiolytic effects). Yet such effects may be sufficient to substitute for ethanol reward derived from its stimulant properties, or they may support ethanol-reinforced behavior in their own right.

\section{Does DA function change with chronic ethanol exposure and withdrawal?}

Over the course of chronic ethanol exposure, adaptations develop in mesolimbic DA function to counter sustained stimulation of this system by ethanol. Although ethanol acutely activates mesolimbic DA neurotransmission, withdrawal from chronic ethanol leads to substantial decrements in VTA DA neuron activity (Diana et al., 1992; Shen and Chiodo, 1993) and extracellular NAc DA levels (Rossetti et al., 1992; Weiss et al., 1996), suggesting that chronic ethanol exposure causes mesolimbic DA hypofunction, a condition significant for maintenance of addiction by promoting ethanol intake to compensate for its deceased efficacy on DA release and by motivating resumption of drinking during withdrawal to reverse DA deficits.

Recent findings have shed light on the mechanisms underlying DA dysregulation during chronic intoxication and withdrawal. Overactivity of L-type calcium channels is a possible mechanism for the suppression of DA release during ethanol withdrawal, because pharmacological inhibition of L-type calcium channels selectively blocks this withdrawal consequence (Rossetti et al., 1999). Decreased expression of tyrosine hydroxylase coupled with elevated levels of DA transporter (DAT) in rats maintained chronically on ethanol-containing diets suggests that decreases in DA synthesis and enhanced clearance of synaptic DA may cause DA hypofunction during ethanol dependence (Rothblat et al., 2001). The latter finding contrasts with results from human alcoholics in whom DAT binding is depressed significantly early in withdrawal but returns to normal with sustained abstinence (Laine et al., 1999). However, DAT binding in humans was measured after $4 \mathrm{~d}$ of withdrawal, whereas DAT expression in rats was determined before withdrawal. Thus, it remains to be determined whether decreased DAT binding is a consequence of chronic drinking or develops to compensate for reductions in DA release during ethanol withdrawal.

DA deficits in subjects with a history of dependence are not restricted to acute ethanol withdrawal but can be long-lasting, as suggested by reduced activity of VTA DA neurons after $3 \mathrm{~d}$ of withdrawal (Diana et al., 1996). Changes in NAc DA turnover and synthesis indicate that decreased DA release is present as long as 2 months after ethanol withdrawal (Bailey et al., 2000). The persistence of such abnormalities may have implications for vulnerability to relapse and adverse symptoms associated with protracted ethanol withdrawal. In clinical studies, a slow rate of recovery of DA receptor function predicts relapse and poor treatment outcome (Heinz et al., 1995). Unfortunately, in both the clinical and preclinical domain, systematic studies linking abnormalities in DA function during protracted withdrawal with ethanol-seeking or other relevant behavioral changes are sparse, but they are needed to understand the behavioral significance of persistent DA dysregulation in the abuse potential of ethanol.

Overall, current evidence suggests that mesolimbic DA transmission represents a substrate for the positive reinforcing actions of ethanol, most notably those associated with the mild stimulant actions of this drug. In addition, counteradaptive changes in mesolimbic dopamine function may provide a mechanism supporting the negative reinforcing aspects of ethanol associated with the dependent state as well as acute and protracted ethanol withdrawal.

\section{Role of the extended amygdala in ethanol reinforcement}

A novel target in the search for neural substrates of ethanol reinforcement is a group of interconnected basal forebrain structures called the extended amygdala, which extend from the NAc shell and bed nucleus of stria terminalis (BNST) to the central amygdala (CeA) (Alheid and Heimer, 1988). Opioid and GABA receptor antagonists administered into the NAc shell, BNST, or CeA reduce alcohol self-administration (Hyytiä and Koob, 1995; Heyser et al., 1999), implicating the extended amygdala in ethanol reinforcement. Ethanol enhances DA release in the CeA (Yoshimoto et al., 2000), and the BNST shows high sensitivity to DAactivating actions of drugs of abuse, including ethanol (Carboni et al., 2000). More direct evidence supporting a role for DA activation in these regions in drug reward exists, but only in the case of cocaine (Koob, 1999); the role of DA in the case of ethanol awaits confirmation by pharmacological and lesion studies.

Focus on the extended amygdala has also provided novel information implicating a role in negative reinforcement by ethanol that is associated with dependence and withdrawal. In addition to counteradaptive changes in neural systems implicated in ethanol positive reinforcement, neuroadaptations in systems not involved in acute reward may contribute to anxiety and other affective changes during withdrawal (Koob and Le Moal, 2001). The CeA and BNST, nuclei that contain a dense network of CRF immunoreactive cells (Swanson et al., 1983), may play a major role in these behavioral changes. Withdrawal from ethanol increases CRF release in CeA (Merlo Pich et al., 1995), and anxiety-like behavior associated with ethanol withdrawal is reduced by intracranial application of the CRF antagonist $\alpha$-helical $\mathrm{CRF}_{9-41}$ (Rassnick et al., 1993) or by deletion of the $\mathrm{CRF}_{1}$ receptor gene (Timpl et al., 1998). Measures of whole-tissue levels of CRF in the $\mathrm{CeA}$ indicate that dysregulation of this system after ethanol withdrawal is persistent (Zorrilla et al., 2001), although the behavioral significance of such changes remains to be established. Similar to the findings in the CeA, extracellular CRF levels in the BNST are elevated during acute ethanol withdrawal, and renewed ethanol consumption normalizes CRF release (Olive et al., 2002). Thus, to the extent that CRF hyperactivity in the BNST may contribute to anxiogenic consequences of ethanol withdrawal, the reversal of this effect by ethanol may contribute to the resumption and maintenance of addictive behavior.

\section{Role of opioid systems in the addictive actions of ethanol}

Interactions between ethanol and opioid systems have been an important focus of neurobiological research on alcohol addiction. Evidence for participation of opioid systems in modulation of ethanol-related behaviors comes from studies of opioid antagonist effects in animal models of ethanol seeking. Both nonselective opioid receptor antagonists and antagonists selective for $\mu$ or $\delta$-opioid receptors (MORs and DORs) reduce ethanol consumption and reinforced responding (for review, see Herz, 1997; Gianoulakis, 2001). Recent data from MOR KO mice favor a role of this receptor in ethanol reward because ethanol consumption, ethanol-reinforced operant responses, and ethanol-stimulated locomotion are decreased (Roberts et al., 2000; Hall et al., 2001). Ethanol self-administration is increased in DOR KO mice (Roberts et al., 2001), yet these mice exhibit an increased anxious- 
like phenotype, but reduced anxiety-like behavior is seen after ethanol self-administration. Thus, reversal of anxiety-like behavior is what may have led to the increased ethanol preference in these mice.

As for ethanol reinforcement, participation of opioid systems is not fully understood, but interactions with NAc DA transmission and DA-independent effects via opioid systems are implicated. Ethanol increases extracellular endorphins in the NAc, suggesting that attenuation of the reinforcing properties of ethanol by opioid antagonists may be related to inhibition of endogenous endorphin actions in the NAc (Olive et al., 2001). Reductions in voluntary drinking by intra-NAc administration of an opioid receptor antagonist (Heyser et al., 1999) or MOR antisense oligonucleotide (Myers and Robinson, 1999) suggest that these inhibitory effects may occur within the NAc. However, such effects may also be dependent on interactions with DA mechanisms. Both systemic (Benjamin et al., 1993) and focal (Acquas et al., 1993) administration of opioid receptor antagonists blunt ethanol-induced DA release within the NAc, implicating this effect in the suppression of ethanol intake by opioid antagonists (Gonzales and Weiss, 1998). On the other hand, selective lesions of DA terminals in the NAc do not alter ethanol selfadministration in rats, but naltrexone reduced ethanol consumption in the same animals (Koistinen et al., 2001). Thus, mechanisms other than interference with DA transmission contribute to the suppressive effects of opiate antagonists on ethanol intake. Although the exact mechanisms by which ethanol increases NAc endorphin levels and by which opioid receptor antagonists exert suppressant effects on drinking have yet to be identified, these results indicate new directions for understanding the effectiveness of opioid receptor antagonists as pharmacological therapies for alcoholism.

On the basis of findings from animal models, naltrexone was tested and found to be effective as a treatment for alcoholism, in terms of both reducing ethanol consumption and preventing relapse (O’Malley et al., 1992; Volpicelli et al., 1992; Anton et al., 1999). However, a recent report (Krystal et al., 2001) cast doubt on the effectiveness of naltrexone. In this large multicenter, double-blind, placebo-controlled evaluation, naltrexone neither prevented nor delayed relapse, nor did it affect other outcome measures. Although this study questions the use of naltrexone, differences between this study and previous positive reports (mostly older men, and more severe alcoholism) likely account for the absence of positive effects. Understanding the neurobiological basis of the actions of naltrexone in human alcoholics, perhaps with new imaging technologies, as well as in animal models that consider the interactions of opioid systems with each stage of ethanol use and abuse, is key.

\section{Incentive motivation, craving, and relapse}

Conditioning of the rewarding effects of ethanol and other drugs of abuse with discrete stimuli is a major factor in abuse potential. Drug-related stimuli evoke drug desire that can lead to resumption of addictive behavior in abstinent individuals (O'Brien et al., 1998). Such stimuli may also elicit automatic responses that lead to drug-seeking and relapse without distinct feelings of craving. Thus, learned responses to drug-related stimuli may be a critical element in the chronic relapsing nature of ethanol and other drug addiction.

In animals, ethanol-associated contextual stimuli (Katner and Weiss, 1999; Ciccocioppo et al., 2001) consistently elicit recovery of responding at a previously ethanol-paired lever after extinction in the absence of further drug availability. Research using reinstatement procedures points to both DA and opioid systems in the motivating effects of ethanol-associated environmental stimuli. In rats, exposure to environments associated with ethanol availability increase extracellular NAc DA levels (Weiss et al., 1993; Gonzales and Weiss, 1998), and alcohol-associated stimuli activate the ventral striatum in abstinent alcoholics (Braus et al., 2001), suggesting that mesolimbic DA transmission may have an important function in mediating behavior that brings the animal into contact with reinforcers. Such a role of DA may be relevant for the initiation of ethanol-seeking by alcohol cues and, by extension, ethanol craving and relapse. Indeed, appetitively motivated behavior preceding delivery of an ethanol solution is more sensitive to reversal by DA D2 receptor antagonists than behavior maintained by ethanol itself (Czachowski et al., 2001). Similarly, the conditioned reinforcing effects of a discrete stimulus previously paired with ethanol-reinforced responses are reversed by the DA receptor antagonist haloperidol (Wilson et al., 2000). A role of DA in relapse associated with exposure to alcohol cues has also been proposed. In rats tested for the response-reinstating effects of an alcohol-associated contextual stimulus after extinction of alcohol-reinforced behavior, blockade of either DA D1 or D2 receptors dose-dependently increases latency to initiate responding and reduces the number of responses at a previously active lever (Liu and Weiss, 2002). These effects of DA receptor blockade mesh well with an emerging view that the function of midbrain DA neurons is to convert motivational signals that predict reward into behavior directed at obtaining the predicted rewarding stimulus (Schultz et al., 1997).

The effects of ethanol-associated contextual stimuli in animal models of relapse are also sensitive to pharmacological manipulation of opioid receptors. The nonselective opioid receptor antagonist naltrexone, as well as MOR- and DOR-selective antagonists, reverses ethanol-seeking induced by ethanol-associated contextual stimuli (Katner et al., 1999; Ciccocioppo et al., 2002). Clearly, opioid receptors participate in ethanol-seeking motivated by drug cues. The fact that the MOR antagonist naloxonazine, but not the DOR antagonist naltrindole, produced nonselective behavioral suppression in these tasks suggests that DORs may be a target for treatment of alcohol craving and relapse (Ciccocioppo et al., 2002). These findings also have a bearing on the extinction hypothesis (Sinclair, 1990), which proposes that the anti-relapse actions of naltrexone are dependent on an associative component whereby subjects learn across repeated trials that ethanol is no longer reinforcing after opioid receptor antagonist administration. There is strong recent support for this hypothesis that has led to the suggestion that longer clinical use of naltrexone may be beneficial in reducing the number of relapse episodes (Stromberg et al., 1998). However, the "intrinsic" anti-relapse efficacy of opioid receptor antagonists in preventing ethanolseeking after a single administration may also contribute to their clinical effectiveness.

Although the neurobiological basis of the ability of cues to produce reinstatement of drinking or drug seeking has been studied primarily in animal models, there are several recent reports of the neural correlates of craving for alcohol produced by olfactory and visual cues (Braus et al., 2001; Mann et al., 2001; Schneider et al., 2001). The results of these studies, however, have been somewhat variable. In one study (Schneider et al., 2001), the presentation of an alcohol olfactory stimulus to newly detoxified alcoholics produced activation within both the amygdala and cerebellum that was reversed by pharmacological and cognitive 
therapy. In contrast, a preliminary report assessing the effects of combined visual and olfactory stimuli to elicit craving in alcoholics identified cortical and thalamic loci (Mann et al., 2001), whereas a third study (Braus et al., 2001) reported effects in the ventral putamen. There is some similarity to the patterns of activation reported in cocaine users when exposed to various drug-related cues (Grant et al., 1996; Childress et al., 1999), but sample sizes and the kinds of paradigms used to elicit craving in alcoholics need to be expanded before we will obtain a consistent pattern of the substrates underlying cue-elicited ethanol craving.

\section{Novel targets}

\section{Endocannabinoids}

Recent evidence has shown that endogenous cannabinoids regulate ingestive behaviors via interactions with leptin (Di Marzo et al., 2001) as well as act as modulators of reward functions (De Vries et al., 2001). A number of reports now have begun to explore the specific relationship between ethanol and cannabinoid systems. Administration of the cannabinoid receptor antagonist, SR141716A, can decrease voluntary ethanol intake in mice (Arnone et al., 1997) as well as in alcohol-preferring rats (Colombo et al., 1998), where it can also prevent the acquisition of drinking behavior (Serra et al., 2001). CB1 receptors have also been shown to be involved in mediating appetitive and consummatory aspects of ethanol ingestion (Freedland et al., 2001), suggesting that SR141716A may have clinical utility in the treatment of alcohol abuse (Freedland et al., 2001). It may also be effective in the prevention of relapse, because SR141716A can be effective in inhibiting reinstatement of drug-seeking behavior elicited by cocaine or cocaine-related cues (De Vries et al., 2001). The mechanism responsible for the suppression of intake of ethanol and cocaine remains to be elucidated, although an interaction of cannabinoids with striatal DA (Giuffrida et al., 1999) is certainly a possibility, but the role of cannabinoids in leptin regulation should also be considered.

\section{Neuropeptide $Y$}

Neuropeptide Y (NPY), like endocannabinoids, is widely distributed throughout the brain (Dumont et al., 1992) and is involved in the control of food intake (Kalra et al., 1991). Of late, NPY has also been implicated in the regulation of ethanol consumption. NPY KO mice show increased voluntary consumption of ethanol, whereas overexpression of NPY yields the opposite result (Thiele et al., 1998). NPY KO mice were also less sensitive to ethanolinduced sedation, whereas mice overexpressing NPY had increased sleep times (Thiele et al., 1998). These effects are the result of interactions specifically with the Y1 NPY receptor subtype (Thiele et al., 2002). Consistent with these findings, rats bred for alcohol preference have reduced levels of NPY specifically within the CeA (Hwang et al., 1990), and the central infusion of exogenous NPY also decreases ethanol drinking in ethanol preferring rats (Badia-Elder et al., 2001). However, alterations of ethanol-related behaviors have not been shown when NPY was administered to nonpreferring or outbred rat strains (Slawecki et al., 2000; Badia-Elder et al., 2001), and the direct injection of NPY into the paraventricular nucleus of the hypothalamus actually increased ethanol consumption (Kelley et al., 2001). Site specificity may underlie these discrepancies, or it may be the case that NPY selectively alters the high ethanol intake of preferring rats via modulation of stress responses. Regardless of their exact mechanisms of action, both endocan- nabinoids and NPY are potential targets for the development of novel therapeutics for the treatment of alcohol abuse.

\section{Concluding considerations}

This review has focused on neurochemical systems and brain circuits that are relevant for alcohol addiction from the perspective of motivation and reinforcement. Ethanol alters synaptic transmission by modulating neuronal excitability through an interaction with ligand and voltage-gated ion channels. As a result, alcohol directly or indirectly affects the function of many neurotransmitter systems in the brain. These actions, and in particular the actions at $\mathrm{GABA}_{\mathrm{A}}, \mathrm{NMDA}$, and serotonin 5-HT3 ionotropic receptors, are of central importance for the addictive effects of ethanol in addition to interactions with the neurochemical systems discussed here. As reviewed elsewhere, important advances have been made in the understanding of the mechanisms of these actions by ethanol and their relevance for alcohol intoxication, tolerance, dependence, and withdrawal (Grant and Lovinger, 1995; Woodward, 2000; Morrow et al., 2001). Understanding the integration of the interactions among these multiple systems in the regulation of ethanol-seeking behavior and the development of ethanol dependence is an important challenge for future research.

\section{REFERENCES}

Acquas E, Meloni M, Di Chiara G (1993) Blockade of $\delta$-opioid receptors in the nucleus accumbens prevents ethanol-induced stimulation of dopamine release. Eur J Pharmacol 230:239-241.

Alheid GF, Heimer L (1988) New perspectives in basal forebrain organization of special relevance for neuropsychiatric disorders: the striatopallidal, amygdaloid and corticopetal components of the substantia innominata. Neuroscience 27:1-39.

Anton RF, Moak DH, Waid LR, Latham PK, Malcolm RJ, Dias JK (1999) Naltrexone and cognitive behavioral therapy for the treatment of outpatient alcoholics: results of a placebo-controlled trial. Am J Psychiatry 156:1758-1764.

Arnone M, Maruani J, Chaperon F, Thiebot MH, Poncelet M, Soubrie P, Le Fur G (1997) Selective inhibition of sucrose and ethanol intake by SR 141716, an antagonist of central cannabinoid (CB1) receptors. Psychopharmacology 132:104-106.

Badia-Elder NE, Stewart RB, Powrozek TA, Roy KF, Murphy JM, Li TK (2001) Effect of neuropeptide Y (NPY) on oral ethanol intake in Wistar, alcohol-preferring (P), and -nonpreferring (NP) rats. Alcohol Clin Exp Res 25:386-390.

Bailey CP, Andrews N, McKnight AT, Hughes J, Little HJ (2000) Prolonged changes in neurochemistry of dopamine neurones after chronic ethanol consumption. Pharmacol Biochem Behav 66:153-161.

Benjamin D, Grant ER, Pohorecky LA (1993) Naltrexone reverses the ethanol-induced dopamine release in the nucleus accumbens in awake, freely moving rats. Brain Res 621:137-140.

Braus DF, Wrase J, Grusser S, Hermann D, Ruf M, Flor H, Mann K, Heinz A (2001) Alcohol-associated stimuli activate the ventral striatum in abstinent alcoholics. J Neural Transm 108:887-894.

Brodie MS, Shefner SA, Dunwiddie TV (1990) Ethanol increases the firing rate of dopamine neurons of the rat ventral tegmental area in vitro. Brain Res 508:65-69.

Brodie MS, Pesold C, Appel SB (1999) Ethanol directly excites dopaminergic ventral tegmental area reward neurons. Alcohol Clin Exp Res 23:1848-1852.

Budygin EA, Phillips PE, Wightman RM, Jones SR (2001) Terminal effects of ethanol on dopamine dynamics in rat nucleus accumbens: an in vitro voltammetric study. Synapse 42:77-79.

Carboni E, Silvagni A, Rolando MT, Di Chiara G (2000) Stimulation of in vivo dopamine transmission in the bed nucleus of stria terminalis by reinforcing drugs. J Neurosci 20:RC102(1-5).

Childress AR, Mozley PD, McElgin W, Fitzgerald J, Reivich M, O'Brien CP (1999) Limbic activation during cue-induced cocaine craving. Am J Psychiatry 156:11-18.

Ciccocioppo R, Angeletti S, Weiss F (2001) Long-lasting resistance to extinction of response reinstatement induced by ethanol-related stimuli: role of genetic ethanol preference. Alcohol Clin Exp Res 25:1414-1419.

Ciccocioppo R, Martin-Fardon R, Weiss F (2002) Effect of selective blockade of $\mu 1$ or $\delta$ opioid receptors on reinstatement of alcoholseeking behavior by drug-associated stimuli in rats. Neuropsychopharmacology, in press. 
Colombo G, Agabio R, Fa M, Guano L, Lobina C, Loche A, Reali R, Gessa GL (1998) Reduction of voluntary ethanol intake in ethanolpreferring SP rats by the cannabinoid antagonist SR-141716. Alcohol Alcohol 33:126-130.

Cunningham CL, Howard MA, Gill SJ, Rubinstein M, Low MJ, Grandy DK (2000) Ethanol-conditioned place preference is reduced in dopamine D2 receptor-deficient mice. Pharmacol Biochem Behav 67:693-699.

Czachowski CL, Chappell AM, Samson HH (2001) Effects of raclopride in the nucleus accumbens on ethanol seeking and consumption. Alcohol Clin Exp Res 25:1431-1440.

De Vries TJ, Shaham Y, Homberg JR, Crombag H, Schuurman K, Dieben J, Vanderschuren LJ, Schoffelmeer AN (2001) A cannabinoid mechanism in relapse to cocaine seeking. Nat Med 7:1151-1154

Diana M, Pistis M, Carboni S, Gessa GL, Rossetti ZL (1992) Profound decrement of mesolimbic neuronal activity during ethanol withdrawal syndrome in rats: electrophysiological and biochemical evidence. Proc Natl Acad Sci USA 90:7966-7969.

Diana M, Pistis M, Muntoni A, Gessa G (1996) Mesolimbic dopaminergic reduction outlasts ethanol withdrawal syndrome: evidence of protracted abstinence. Neuroscience 71:411-415.

Di Chiara G, Imperato A (1988) Drugs abused by humans preferentially increase synaptic dopamine concentrations in the mesolimbic system of freely moving rats. Proc Natl Acad Sci USA 85:5274-5278.

Di Marzo V, Goparaju SK, Wang L, Liu J, Batkai S, Jarai Z, Fezza F, Miura GI, Palmiter RD, Sugiura T, Kunos G (2001) Leptin-regulated endocannabinoids are involved in maintaining food intake. Nature 410:822-825.

Dumont Y, Martel JC, Fournier A, St. Pierre S, Quirion R (1992) Neuropeptide $\mathrm{Y}$ and neuropeptide $\mathrm{Y}$ receptor subtypes in brain and peripheral tissues. Prog Neurobiol 38:125-167.

El-Ghundi M, George SR, Drago J, Fletcher PJ, Fan T, Nguyen T, Liu C, Sibley DR, Westphal H, O’Dowd BF (1998) Disruption of dopamine D1 receptor gene expression attenuates alcohol-seeking behavior. Eur J Pharmacol 353:149-158.

Engleman EA, McBride WJ, Wilber AA, Shaikh SR, Eha RD, Lumeng L, Li TK, Murphy JM (2000) Reverse microdialysis of a dopamine uptake inhibitor in the nucleus accumbens of alcohol-preferring rats: effects on dialysate dopamine levels and ethanol intake. Alcohol Clin Exp Res 24:795-801.

Freedland CS, Sharpe AL, Samson HH, Porrino LJ (2001) Effects of SR141716A on ethanol and sucrose self-administration. Alcohol Clin Exp Res 25:277-282.

Gessa GL, Muntoni F, Collu M, Vargiu L, Mereu G (1985) Low doses of ethanol activate dopaminergic neurons of the ventral tegmental area. Brain Res 348:201-203.

Gianoulakis C (2001) Influence of the endogenous opioid system on high alcohol consumption and genetic predisposition to alcoholism. J Psychiatry Neurosci 26:304-318.

Giuffrida A, Parsons LH, Kerr TM, Rodriguez de Fonseca F, Navarro M, Piomelli D (1999) Dopamine activation of endogenous cannabinoid signaling in dorsal striatum. Nat Neurosci 2:358-363.

Gonzales RA, Weiss F (1998) Suppression of ethanol-reinforced behavior by naltrexone is associated with attenuation of the ethanol-induced increase in dialysate dopamine levels in the nucleus accumbens. J Neurosci 18:10663-10671.

Grant KA, Lovinger DM (1995) Cellular and behavioral neurobiology of alcohol: receptor-mediated neuronal processes. Clin Neurosci 3:155-164.

Grant S, London ED, Newlin DB, Villemagne VL, Liu X, Contoreggi C, Phillips RL, Kimes AS, Margolin A (1996) Activation of memory circuits during cue-elicited cocaine craving. Proc Natl Acad Sci USA 93:12040-12045

Hall FS, Sora I, Uhl GR (2001) Ethanol consumption and reward are decreased in mu-opiate receptor knockout mice. Psychopharmacology 154:43-49.

Heinz A, Lichtenberg-Kraag B, Baum SS, Graf K, Kruger F, Dettling M, Rommelspacher H (1995) Evidence for prolonged recovery of dopaminergic transmission after detoxification in alcoholics with poor treatment outcome. J Neural Transm Gen Sect 102:149-157.

Herz A (1997) Endogenous opioid systems and alcohol addiction. Psychopharmacology 129:99-111.

Heyser CJ, Roberts AJ, Schulteis G, Koob GF (1999) Central administration of an opiate antagonist decreases oral ethanol selfadministration in rats. Alcohol Clin Exp Res 23:1468-1476.

Hwang BH, Lumeng L, Wu JY, Li TK (1990) Increased number of GABAergic terminals in the nucleus accumbens is associated with alcohol preference in rats. Alcohol Clin Exp Res 14:503-507.

Hyytiä P, Koob GF (1995) GABAA receptor antagonism in the extended amygdala decreases ethanol self-administration in rats. Eur J Pharmacol 283:151-159.

Ikemoto S, McBride WJ, Murphy JM, Lumeng L, Li TK (1997) 6-OHDA-lesions of the nucleus accumbens disrupt the acquisition but not the maintenance of ethanol consumption in the alcohol-preferring $\mathrm{P}$ line of rats. Alcohol Clin Exp Res 21:1042-1046.
Kalra SP, Dube MG, Sahu A, Phelps CP, Kalra PS (1991) Neuropeptide $Y$ secretion increases in the paraventricular nucleus in association with increased appetite for food. Proc Natl Acad Sci USA 88:10931-10935.

Katner SN, Weiss F (1999) Ethanol-associated olfactory stimuli reinstate ethanol-seeking behavior after extinction and modify extracellular dopamine levels in the nucleus accumbens. Alcohol Clin Exp Res 23:1751-1760.

Katner SN, Magalong JG, Weiss F (1999) Reinstatement of alcoholseeking behavior by drug-associated discriminative stimuli after prolonged extinction in the rat. Neuropsychopharmacology 20:471-479.

Kelley SP, Nannini MA, Bratt AM, Hodge CW (2001) Neuropeptide-Y in the paraventricular nucleus increases ethanol self-administration. Peptides 22:515-522.

Koistinen M, Tuomainen P, Hyytia P, Kiianmaa K (2001) Naltrexone suppresses ethanol intake in 6-hydroxydopamine-treated rats. Alcohol Clin Exp Res 25:1605-1612.

Koob GF (1999) The role of the striatopallidal and extended amygdala systems in drug addiction. Ann NY Acad Sci 877:445-460.

Koob GF, Le Moal M (2001) Drug addiction, dysregulation of reward, and allostasis. Neuropsychopharmacology 24:97-129.

Krystal JH, Cramer JA, Krol WF, Kirk GF, Rosenheck RA (2001) Naltrexone in the treatment of alcohol dependence. N Engl J Med 345:1734-1739

Laine TP, Ahonen A, Torniainen P, Heikkila J, Pyhtinen J, Rasanen P, Niemela O, Hillbom M (1999) Dopamine transporters increase in human brain after alcohol withdrawal. Mol Psychiatry 4:189-191.

Liu X, Weiss F (2002) Reversal of ethanol-seeking behavior by D1 and D2 antagonists in an animal model of relapse: differences in antagonist potency in previously ethanol-dependent vs nondependent rats. J Pharmacol Exp Ther 300:882-889.

Mann K, Agartz I, Harper C, Shoaf S, Rawlings RR, Momenan R, Hommer DW, Pfefferbaum A, Sullivan EV, Anton RF, Drobes DJ, George MS, Bares R, Machulla HJ, Mundle G, Reimold M, Heinz A (2001) Neuroimaging in alcoholism: ethanol and brain damage. Alcohol Clin Exp Res 25:104S-109S.

McBride WJ, Li TK (1998) Animal models of alcoholism: neurobiology of high alcohol-drinking behavior in rodents. Crit Rev Neurobiol $12: 339-369$

Merlo Pich E, Lorang MT, Yeganeh M, De Fonseca FR, Raber J, Koob GF, Weiss F (1995) Increase of extracellular corticotropin-releasing factor-like immunoreactivity levels in the amygdala of awake rats during restraint stress and ethanol withdrawal as measured by microdialysis. J Neurosci 15:5439-5447.

Morrow AL, VanDoren MJ, Penland SN, Matthews DB (2001) The role of GABAergic neuroactive steroids in ethanol action, tolerance and dependence. Brain Res Brain Res Rev 37:98-109.

Myers RD, Robinson DE (1999) Mu and D2 receptor antisense oligonucleotides injected in nucleus accumbens suppress high alcohol intake in genetic drinking HEP rats. Alcohol 18:225-233.

O’Brien CP, Childress AR, Ehrman R, Robbins SJ (1998) Conditioning factors in drug abuse: can they explain compulsion? J Psychopharmaco 12:15-22.

Olive MF, Koenig HN, Nannini MA, Hodge CW (2001) Stimulation of endorphin neurotransmission in the nucleus accumbens by ethanol, cocaine, and amphetamine. J Neurosci 21:RC184(1-5).

Olive MF, Koenig HN, Nannini MA, Hodge CL (2002) Elevated extracellular CRF levels in the bed nucleus of the stria terminalis during ethanol withdrawal and reduction by subsequent ethanol intake. Pharmacol Biochem Behav 72:213-220.

O'Malley SS, Jaffe AJ, Chang G, Schottenfeld RS, Meyer RE, Rounsaville B (1992) Naltrexone and coping skills therapy for alcohol dependence. Arch Gen Psychiatry 49:881-888.

Rassnick S, Heinrichs SC, Britton KT, Koob GF (1993) Microinjection of a corticotropin-releasing factor antagonist into the central nucleus of the amygdala reverses anxiogenic-like effects of ethanol withdrawal. Brain Res 605:25-32.

Risinger FO, Freeman PA, Rubinstein M, Low MJ, Grandy DK (2000) Lack of operant ethanol self-administration in dopamine D2 recepto knockout mice. Psychopharmacology 152:343-350.

Risinger FO, Freeman PA, Greengard P, Fienberg AA (2001) Motivational effects of ethanol in DARPP-32 knock-out mice. J Neurosc 21:340-348

Roberts AJ, McDonald JS, Heyser CJ, Kieffer BL, Matthes HW, Koob GF, Gold LH (2000) mu-Opioid receptor knockout mice do not selfadminister alcohol. J Pharmacol Exp Ther 293:1002-1008.

Roberts AJ, Gold LH, Polis I, McDonald JS, Filliol D, Kieffer BL, Koob GF (2001) Increased ethanol self-administration in delta-opioid receptor knockout mice. Alcohol Clin Exp Res 25:1249-1256.

Rossetti ZL, Hmaidan Y, Gessa GL (1992) Marked inhibition of mesolimbic dopamine release: a common feature of ethanol, morphine cocaine and amphetamine abstinence in rats. Eur J Pharmaco 221:227-234.

Rossetti ZL, Isola D, De Vry J, Fadda F (1999) Effects of nimodipine on extracellular dopamine levels in the rat nucleus accumbens in ethanol withdrawal. Neuropharmacology 38:1361-1369. 
Rothblat DS, Rubin E, Schneider JS (2001) Effects of chronic alcohol ingestion on the mesostriatal dopamine system in the rat. Neurosci Lett 300:63-66.

Schneider F, Habel U, Wagner M, Franke P, Salloum JB, Shah NJ, Toni I, Sulzbach C, Honig K, Maier W, Gaebel W, Zilles K (2001) Subcortical correlates of craving in recently abstinent alcoholic patients. Am J Psychiatry 158:1075-1083.

Schultz W, Dayan P, Montague PR (1997) A neural substrate of prediction and reward. Science 275:1593-1599.

Serra S, Carai MA, Brunetti G, Gomez R, Melis S, Vacca G, Colombo G, Gessa GL (2001) The cannabinoid receptor antagonist SR 141716 prevents acquisition of drinking behavior in alcohol-preferring rats. Eur J Pharmacol 430:369-371.

Shen RY, Chiodo LA (1993) Acute withdrawal after repeated ethanol treatment reduces the number of spontaneously active dopaminergic neurons in the ventral tegmental area. Brain Res 622:289-293.

Sinclair JD (1990) Drugs to decrease alcohol drinking. Ann Med 22:357-362.

Slawecki CJ, Betancourt M, Walpole T, Ehlers CL (2000) Increases in sucrose consumption, but not ethanol consumption, following ICV NPY administration. Pharmacol Biochem Behav 66:591-594.

Stromberg MF, Volpicelli JR, O'Brien CP (1998) Effects of naltrexone administered repeatedly across 30 or 60 days on ethanol consumption using a limited access procedure in the rat. Alcohol Clin Exp Res 22:2186-2191.

Swanson LW, Sawchenko PE, Rivier J, Vale WW (1983) Organization of ovine corticotropin-releasing factor immunoreactive cells and fibers in the rat brain: an immunohistochemical study. Neuroendocrinology 36:165-186.

Thiele TE, Marsh DJ, St. Marie L, Bernstein IL, Palmiter RD (1998) Ethanol consumption and resistance are inversely related to neuropeptide Y levels. Nature 396:366-369.

Thiele TE, Koh MT, Pedrazzini T (2002) Voluntary alcohol consumption is controlled via the neuropeptide $\mathrm{Y}$ Y1 receptor. J Neurosci 22:RC208(1-6).
Timpl P, Spanagel R, Sillaber I, Kresse A, Reul JM, Stalla GK, Blanquet V, Steckler T, Holsboer F, Wurst W (1998) Impaired stress response and reduced anxiety in mice lacking a functional corticotropinreleasing hormone receptor. Nat Genet 19:162-166.

Volpicelli JR, Alterman AI, Hayashida M, O'Brien CP (1992) Naltrexone in the treatment of alcohol dependence. Arch Gen Psychiatry 49:876-880.

Weiss F, Lorang MT, Bloom FE, Koob GF (1993) Oral alcohol selfadministration stimulates dopamine release in the rat nucleus accumbens: genetic and motivational determinants. J Pharmacol Exp Ther 267:250-258.

Weiss F, Parsons LH, Schulteis G, Lorang MT, Hyytiä P, Bloom FE, Koob GF (1996) Ethanol self-administration restores withdrawalassociated deficiencies in accumbal dopamine and serotonin release in dependent rats. J Neurosci 16:3474-3485.

Williams-Hemby L, Porrino LJ (1997) I. Functional consequences of intragastrically administered ethanol in rats as measured by the 2-[14C]deoxyglucose method. Alcohol Clin Exp Res 21:1573-1580.

Wilson AW, Costall B, Neill JC (2000) Manipulation of operant responding for an ethanol-paired conditioned stimulus in the rat by pharmacological alteration of the serotonergic system. J Psychopharmacol $14: 340-346$

Woodward JJ (2000) Ethanol and NMDA receptor signaling. Crit Rev Neurobiol 14:69-89.

Yim HJ, Gonzales RA (2000) Ethanol-induced increases in dopamine extracellular concentration in rat nucleus accumbens are accounted for by increased release and not uptake inhibition. Alcohol 22:107-115.

Yoshimoto K, Ueda S, Kato B, Takeuchi Y, Kawai Y, Noritake K, Yasuhara M (2000) Alcohol enhances characteristic releases of dopamine and serotonin in the central nucleus of the amygdala. Neurochem Int 37:369-376.

Zorrilla EP, Valdez GR, Weiss F (2001) Changes in levels of regional CRF-like immunoreactivity and plasma corticosterone during protracted drug and alcohol withdrawal in dependent rats. Psychopharmacology, in press. 